[Citellns dauricns mongolicus Milne-Edwards; Susliks]、長爪沙鼠[Meriones unguiculatus(Milne-Edwards); Gerbils]、霄忽[Ochotona d. daurica(Pallas); Mouse-hare]及白氏田鼠[ $[M i$ crotus brandtii(Radde);Btandt's Field Vole]、 地鼠 [Cricetulus sp.]等,次娎的有跳鼠[Dipus sagitta sowerbyi Thomas; Three-toed Jerboa]、 路鼠 [Allactaga sibirica subsp.; Five-toed Jerboa]盲鼠[Myospalax sp.; Mole-rat] 等,其 中以黃鼠分作最廣，所有的工作地區均見有之，而 且數目亦最多。

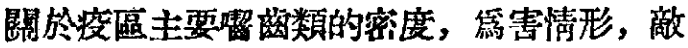
害，生活習性，捕捉方法以及生活史等，亦算有初 步調查,現何在繼續研究中。

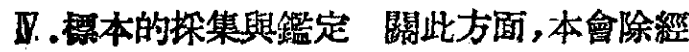

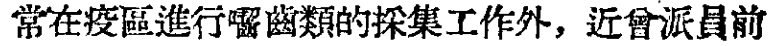
往源縣調查關於草魚的繁殖問題，並協同河北街 水鏟局，進行沿海一帶動物標本的探集。本會委員

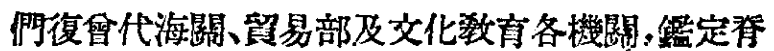
椎動物標本，並協助科學館、博物館等，設計陳列 與展覽。此外，本會工作人員近承科學院編摆局 名詞組委托，担任關於瓷椎野物的系統命名工作， 其目的在使此類動物的分類名稳能够統一, 以便 利生物學學，及國內生物資源調查與動物分類 研究。

追溯本會工作，自成立至今，初期重點在於檡 本的系粒排置與初步整理。現正計劃從事專類垛 集及專題分類研究, 並挨與中央自然博物刢保持 工作上必要的聯獒，以共謀我國動物分類研究的 發展。

(渎作新)

\title{
山東利津王莊的堵口工程
}

\section{一 凌汛及决口情况}

1951年1月，連降大等，天氣極冷，黄河的水， 都凍住了。一月下旬, 天莱突轉和䁔,封凍的冰, 叉 自上而下，逐漸解凍。到30日，已由本原省開到山

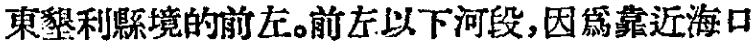
，位置漏北，氣候特别冷，仍舊封結着。因此上游大 量冰凌，擁擠在前左一洮，水位抬高到兩公尺多。 踓經使用大量炸樂，進行爆炸，因段落太長，汥有 收到資效。31日，冰凌繼續攡挤,漸到東張莊一帶，

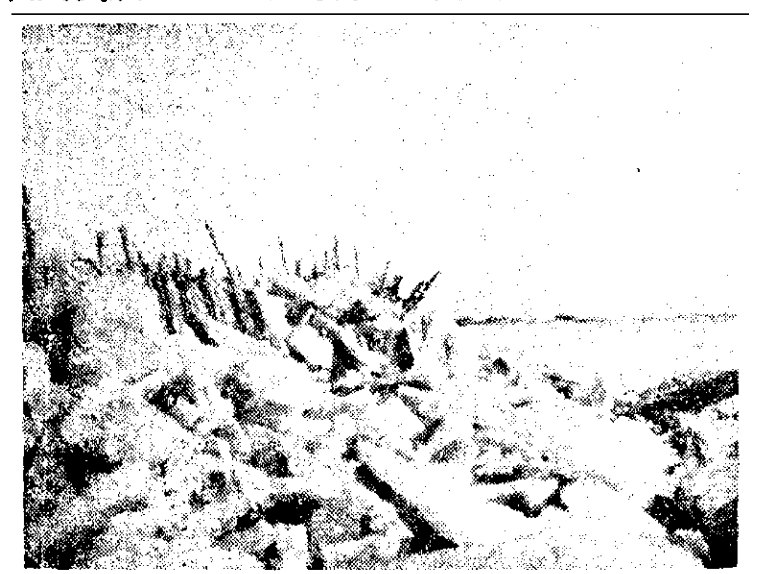

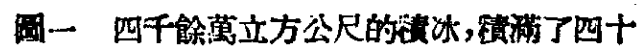
多菲里的橫河河道, 巨大體稘的枨塊， 稭境、堤項，造成黃河决口前的 的雷形繁。

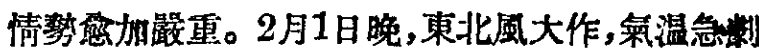
降低,擁僢着的冰淩，又被凍結。自前左到察海 40 里的河道，都成了水山，水流完全堵住。因此管海 以上水位，一遖上碾。到2日晚上,已超壮1949年洪

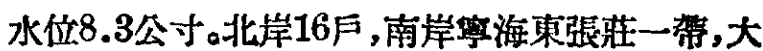
隄出水祇二、三公寸,大塊冰凌，已經有掖到踶項 以上來的。情勢已經極篇險惡，而在蔣莊、芭家溸、 西張、東張、章邱屋子等13處文發生了漏洞，經我

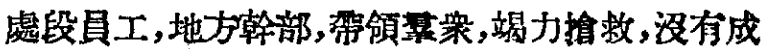
苂。2日夜11時,利津北岸王荘險工下首三百餙公 尺的地方，及發現漏洞三佔。當經處段員工州餘 人，民工三百餘人，奪力搶堵，但是因篇通個時侯 䧄河水面，還凍結着，不能立刻查出漏洞進水的 所在地。背河出水口，又因箳然力過大，急切不易

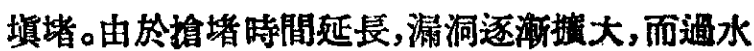
亦㙰多忿急，終至搶堵不及。隄身十餘公尺，全部 崩埸，醇成决口。工程榢及民工多人，均随隄陷入 水內，踓然大多遇救，可是工程隊員一人，村舆一 人,民兵一人，都不幸犃牲了。

\section{二 被災區域災民之塔救與安貫}

请水出口，流分兩股，一向東北，一向西北,再 在八里莊附近，滩合感一。在山東露化縣境的垛 


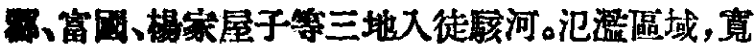

- 約14公里.辰䄪40公里。淹及利津、露化兩縣共計

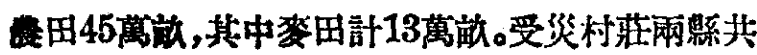
計99付，倒锡房屋34,560間。被桨人口計 6,8780 人， 已查明淹死的有 18 人，食糧物㗄損失一部分，彩猪

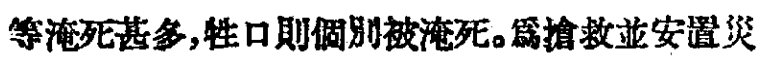
民，山東省政府立即建站搶救指㧫部，利津、露化

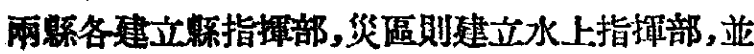
分甽設立收容所六處，斯廠一所，不少村荘，成立

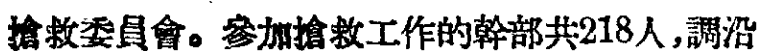
河民船358隻，船工1,598人。於20天內即完成災

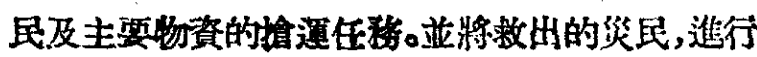

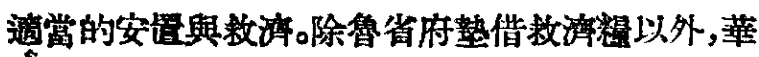

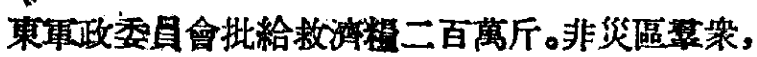
自動据熱乾糃20,644斤，糧食20,000斤，烓柴19,8

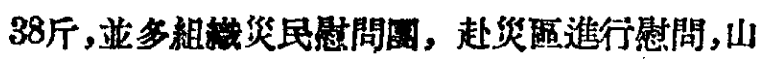

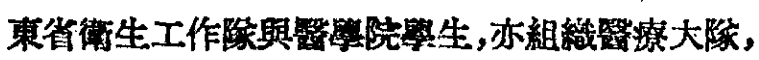
深入災區,12天當中，共治療 2,265 人。

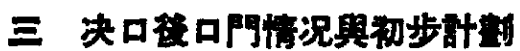

决口地點在山東利津黃河北岸王莊险工下首 380公尺的地方，口門寬216公尺，口門溜勢，東增

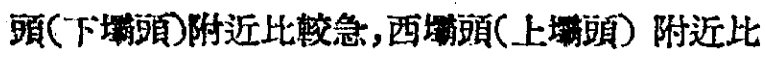
较緩,在西搠頚附近，水深8公尺，中部水深13公

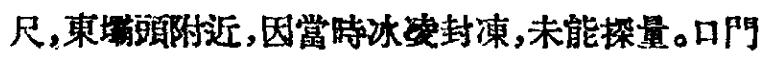
以下正河冰凍谌堅，水溜不通，所以口門已成全河 奪溜的形勢。口閒以外，溃水深自牛公尺至二公尺 不等。口門以上大河流重估計約 600 秒公方。根㨜

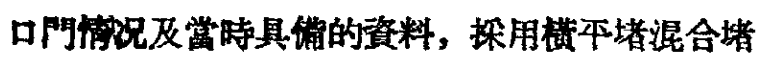

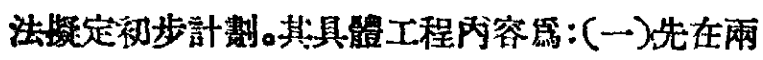

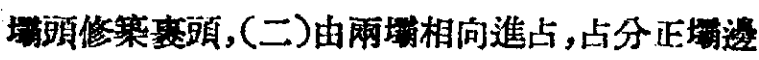

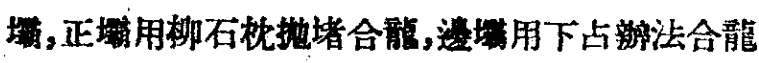

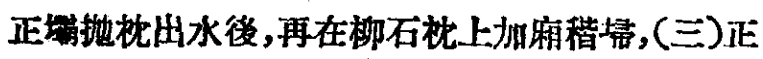

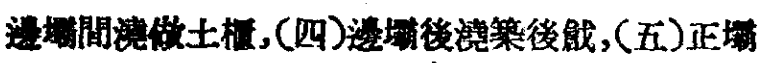

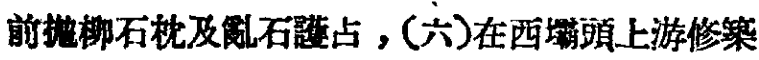

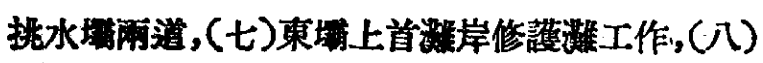

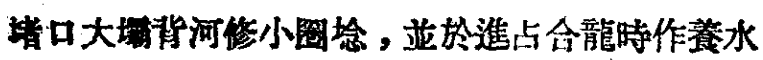

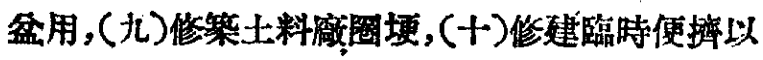
利兩瀻喕與正河對岸之交通。以上各項工程工料

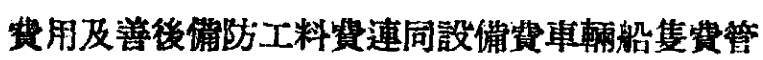

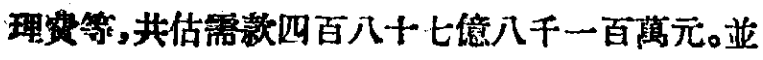

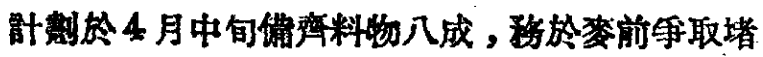

口合龍。

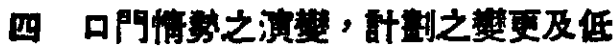 訝進占合晀進行情况}

3 月初旬以後，口門以下正河冰淩逐濑解凍， 部分河水，又循大河正道下流，口門情勢亦随之日 好轉。3月18日，望测口門流量，紙有104秒公方， 䄪佔全河流量之一成,比之初决的時解，已經十去 $+4$

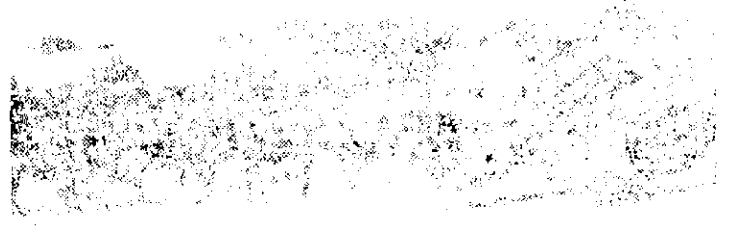

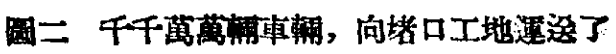

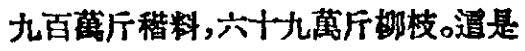
運稭料之大車的一部。

其九。口門最大深度祇有九公尺,亦比較初决的時 读減少四分之一。由於工情的等化大見好轉，提前

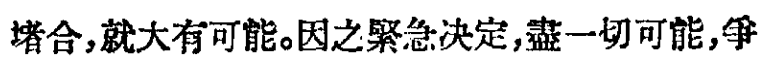
取在桃汎以前，相機搶堵合龍，耤以避负桃沉水涨 炎區損失之演大。接着就進行研究關於搶㗪的具 能方法。造個時候，口門流量，踓然已大䈍娍少，而

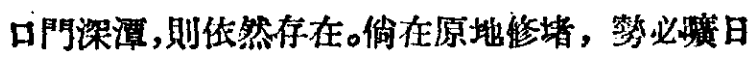
紫时，難得速成，惟有避開深潭，另外摆水淺的地 方施工，方稱相宜。因之，臨特决定，改在口門以下 三百公尺處進行唅堵。(該處水深的二公尺餘) 拾

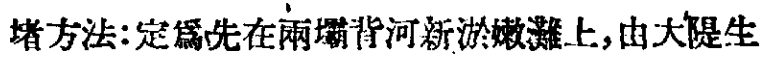
根，修成婘隄，再出東西兩园隄頭，相向進占，進占 時一律用單罚，隨後跟繞後战，合散探用下占辦法，

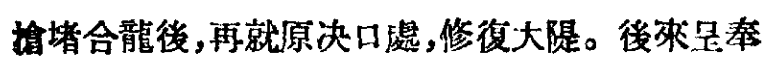

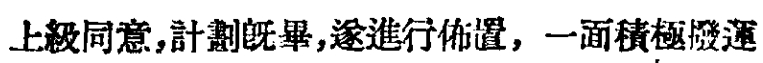
料物，一面迅速調集民工，並規定3月21日，關始興 工。後來因第開工期逼近，河水突然上涨。背河兩

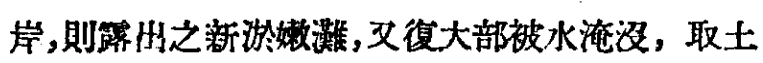
既有困難，形勢亦有變化，所以就暫粰施工。後柬 又㨲量口門上首水深，一般都在一公尺左右，如果 能前堵，尤其來得有利。亚且能縮短時間，於是郜 時决定，改用相機前進堵法。前進搶堵之具能計亚 
，瓷先在擬定拾堵地址上首10-20公尺處，修筑

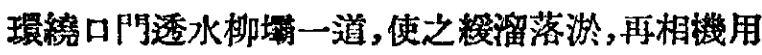
單碖進占合龍，合龍後再修復口聞大隄。除此之外，

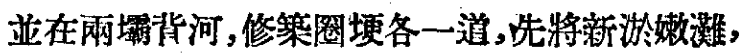
圈出了部，以供取土存料之用。3月22日，圍埂工

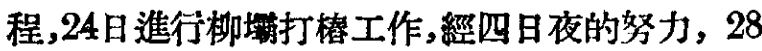
日打楱完畢。29日進行編柳工作，才不過牛天，編 柳出水，時以口門附近,河水大落,新淤制灘,多牛 露出水面。口阿過水的地方，僅剩兩溝，計其總宽， 不過一百公尺，深度一般祇有一公尺餘，淺處向不 及一公尺。流速最大不超過五公寸。情况良好，似 乎稍事唅堵，即可斷流。因之即刻决定利用楖㙩雨 排木椿，就中搶拖廐袋，淮行拾堵，試使斷流，期以 最小的代價，換取最大之成功。這储時候，涉水工 作的民工、工程降、幹部，不下一千餘人，無不爭先 恐後,禽勇直前,踓如冰河水,冷澈肌骨。也不會稍 有退繀。浔有多少時候,有一漬被堵中斷, 不料河
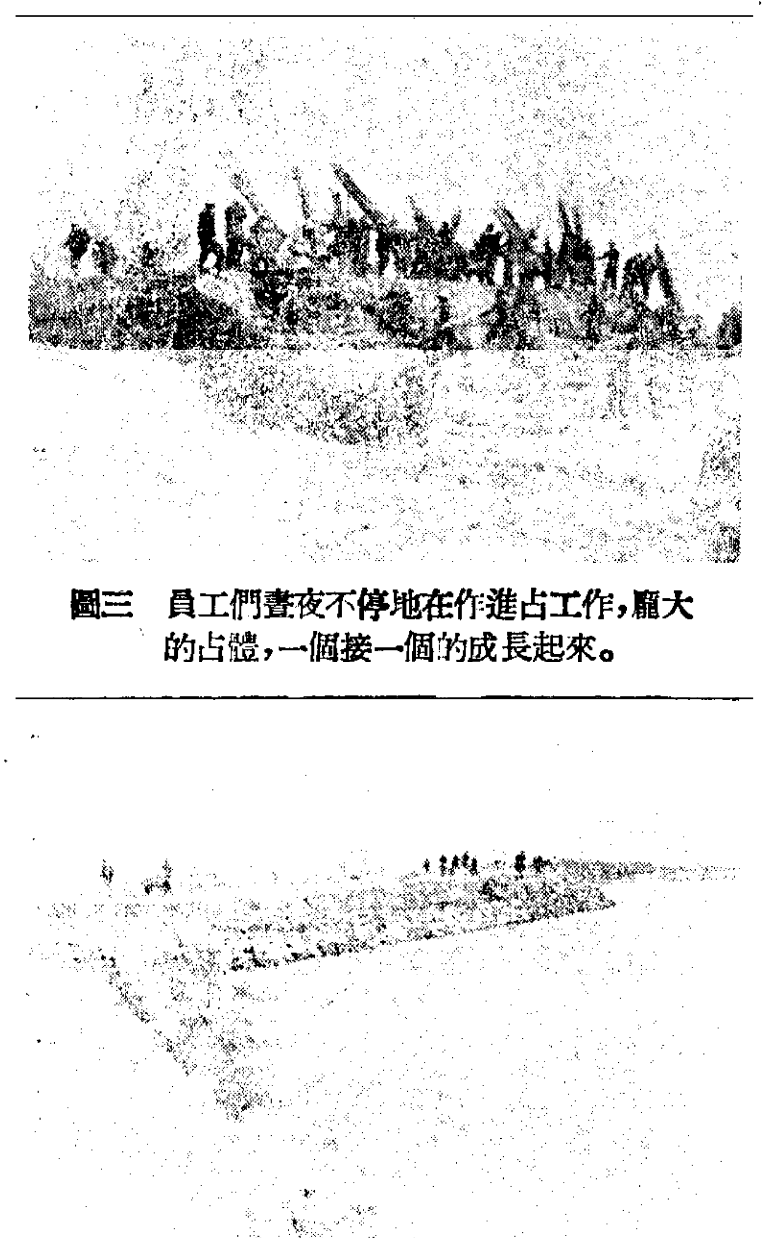

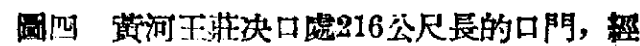
七千餘員工六畫夜的期苦整同，淮占十

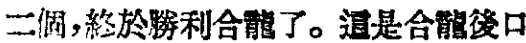
閒之全景。

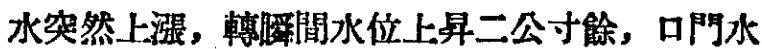

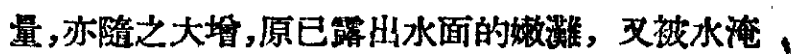
涩，情樊惡化，再拖也沼有好處，因此即聚急决定， 不再續执。第二天河水退落，探量正口門處水深， 也祆不過二、三尺。從前的深潭,已經不復仔在。此 較口問上首水深，亦已無大差别。因此改在 正口 門處施工堵合,但如口閏前果有更好機會,自仍照 前議,進行前堵,先使斷流。關於正口門處之堵合

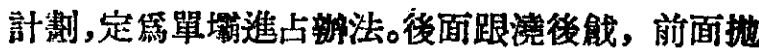
石護根，合龍仍用下占竬法。無論占工後餢，因㺓 期桃沉以前堵合，所以都暫定修隄及悠築其他善

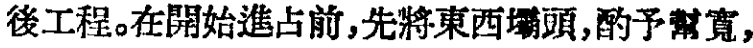

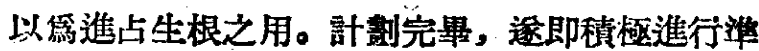
偖，於4月1日，開始由兩埥進占，畫夜唅堵，6日晚 兩壦占工全部完成,7日晨5時20分,開始合龍,7時 合龍占到底，惟餘占䋖過水，急如泉涌，湧起之高， 不下四、五寸，賞即集中力量，搶拖麻袋，8時牛，兩

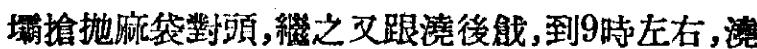
剑出水，搶堵閉篓。到是堵口大工，行得勝利完成， 計算時關。阙好是决口後第64天。堵策之速，赛在 是黄河史上所少有的。

\section{五 誉後工程}

低㙁進占合龍後，雼保登口䦦附近，'不再请 决,决定繼維淮行以下未完工程：

（甲）就原有占面，以稭料加高，並分段作成魚

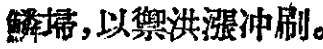

(乙)加拖王莊險工下首自 56 號至 68 號各场

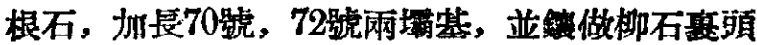
,以便挑溜外移,屏障口門。

(丙)修復口聞大隄，並加筑後解。

（丁）根㨜䥊探結果，口門內外距地面 4-7公 尺處，有策朽稭料一㕣，係過去合龍之舊占工。厚 自1一2公尺。篇安全起見,在背河新策套隄,將該 段環繞於內,以免再生意外。

(戊)口聞以下約二公里處, 有光緒21年合龍

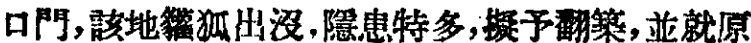
有後能, 加筧延長，上至新套隄與大隄交义處，下。 至老董大隄轉禁處。

(己)堆集土中, 以隹急需。

以上各项工程，現正進行中，頊計5月20日以 前,即可完全埈工。 


\section{六 提前墙合腾利原因}

此次提前堵合勝利之主要因素, 有以下三者:

(甲)上級黨與政府正確領導及争取提前合龍 方針之正確: 上級領導譏關自中央到地方，始終未

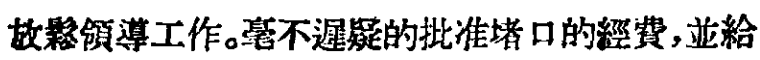
予各璉堵筑指示, 調墢各種料物器材。菲東及山東 省政府，在中央經資未报到前，提前熱借互款，以 便借料。各兄弟画，亦克分協助，不遺餘力。此次料 物動員，南達渴漢北及北京、天津、東北，西到開封， 東到青島, 造是國民黨與蔣政附時代所不能作到 的。ll東政府堅定不移的一再指示與鼓啀，因之不 諭堵策方圷上有何分枝意見，不論計劃如何變更， 最後則均䟽一到此一方針，並遵循此方針，具體組 轺與行動。

（乙）幹部工人之積政努力與帶頭：此次堵口 工程中,所有幹部工人,都爭先恐後, 參加工作。在

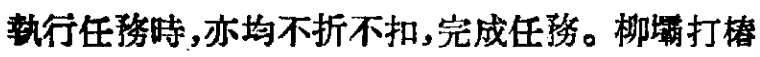
之工程隊員，在早晨少有薄冰的天氧赛，整日泡在
黄水中，起了帶䫓推動作用。口阿渡河民:士.下

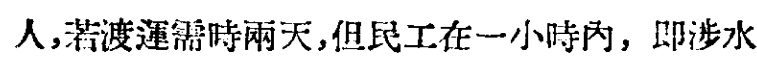
渡過，如無高度積極性，難有這樣数人的事䟖。電 嬁工人在電機浑到三小時之內, 就能阴澄。過河電 話䋐斷折,工人不避危險, 在夜間立刻接上，總尘

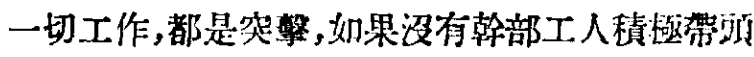
與推動,則桃沉前合龍,算在是不可能的。

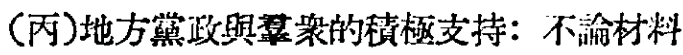
與人工慗啥有啥,源源供給, 保證了供應。地工镇 極性, 也異乎潯常, 不諭運料挑土都是快步湔進, 而且挑的筐很渶。有很多人挑拾筐, 趾經勤占, 仍 有不少人堅持,所以工作效茶,空前提宫。

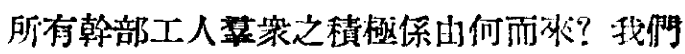
認篇是四年來人民治黄成果的具嗄表現。更重要

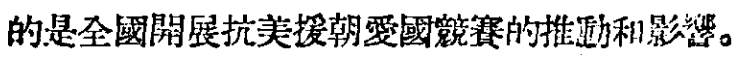

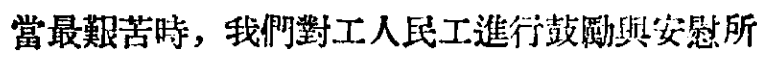
得的回答是: “志願軍在朝鮮比我們還萿，我们要 在堵口立功。”

（山東黄河河務局涌訊組）

\section{組織療法的試驗報導}

S內科椟生異常的耀耀着他的眼睛, 以最快的 速度,讀完了一篇文章的鉛字，之後他忽然做着深 呼吸,沉默的想了一會。原來他在第11期的“前進” 雜誌中,知道了蘇聯醫蛽革命, 冾藏植皮療法(即 䢸織療法)的令人第巽的報䓕文草，遭件事乃惹起 了他的十二分的注意。

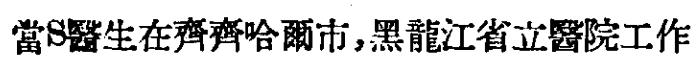

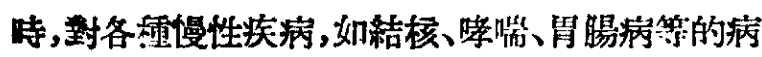

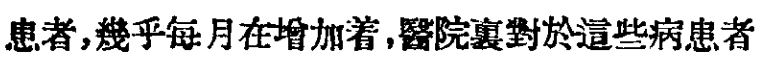
是繁资苦心的。踓然每年都有激的療法發表了，而 探用之後, 結果却均不能滿足的。如宣傳得很厲害 的鍕徽素, 說是結核病的特效葯, 可是費用既昂, 效用也不一定有把暒, 總不是理想的䒬物。而且患 病者，還需要長期休秦的抵抗奖病的耐心，時常使 人感到煩閔。㽞生們也感到慢性病與急性病有些 不同,病情的侅化很少，致治療病人的工作情緒， 也就低柾了。他自知道有組織潦法之後, 是是喜出 望外，像在沙漠中弡現称洲似的喜㤝。

第二天一起早, 他立即拿着那一期的“前進”
新誌去與醫院院長洽談, 而且常面提出了要進行

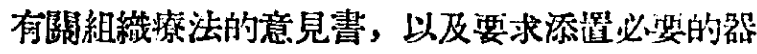
材的請求書,他馬上得到院長的同意和嵮㢦，他一

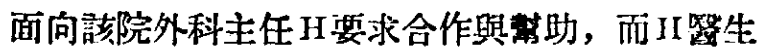

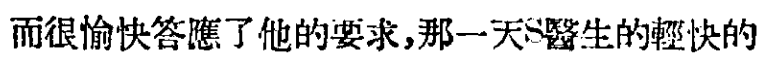
心情是難以想像的。

在中國报起全國規模的抗美搝朝，展䍀生流 競賽運動之後，這侗醫院寒的日本人學望小組,在 這偉大運動的賞中，S 醫生也以普遍推行組䋘潦

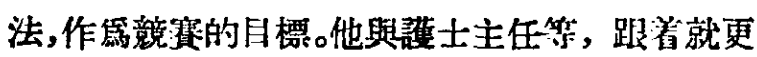
深入了病房, 將㑤萑聯專家所發明的療法, 而且在日 本,已由日共所領導的醫院,在廣泛的嫄用着, 亚

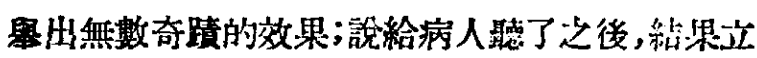
刻有三名患者同意接受這個澵的塐法，一、二、三、 日內就有十數名欣然接受道储療法了, 每個病人 都要求S醫生早日施行逜個療法。

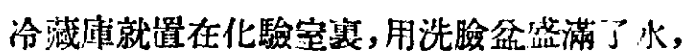
在室外放了一夜,就凍成冰了，(這是指冬委加猝 哈爾市而言,譯者噇)，冾藏㡷內保持捧氏三度左
- 880 •
科學通報
第二亜 